\title{
Modeling Influential Factors on Learner Autonomy in Oral English in the Chinese EFL Context
}

\author{
Chun Zeng ${ }^{1} \&$ Chunyan Liu $^{2}$ \\ ${ }^{1}$ School of Foreign Languages, Jiangxi Science \& Technology Normal University, Hongjiaozhou District, Nanchang, \\ China \\ 2 Foreign Languages College, Jiangxi Normal University, 99 Ziyang Avenue, Nanchang, China
}

Correspondence: Chunyan Liu, Foreign Languages College, Jiangxi Normal University, 99 Ziyang Avenue, Nanchang, China. Tel: 86-139-7084-2533. E-mail: lcy8506552@163.com

Received: December 2, 2014

Accepted: December 12, 2014

Online Published: December 13, 2014

doi:10.5430/elr.v3n2p103

URL: http://dx.doi.org/10.5430/elr.v3n2p103

\begin{abstract}
This study involves a large-scale investigation of influential factors on learner autonomy in oral English (LAIOE) for students in China. A questionnaire was sent to 478 English majors from 7 different universities or colleges. The questionnaire included 6 sub-scales, investigating LAIOE and the five factors: self-efficacy on oral ability, attribution on oral ability, teachers, peers and atmosphere in class and awareness on oral autonomy. Validation of the questionnaire involved exploratory factor analyses on thje dataset collected in a pilot study. A hypothesized path model integrating LAIOE and five influencing factors was tested by using stepwise regression analyses. The results show that the five influencing factors are all significantly and positively correlated with LAIOE. Among them, self-efficacy is the most powerful predictor of LAIOE. The teacher factor, attribution and awareness could significantly and positively predict LAIOE; the teacher factor could predict peers and class atmosphere, and attribution; peers and class atmosphere, as well as attribution, could predict self-efficacy directly and impact LAIOE indirectly. The results shed light on individual and contextual variables to account for learner autonomy in speaking English in the EFL context such as China.
\end{abstract}

Keywords: English majors, Learner autonomy in oral English, Influencing factors, Path model

\section{Introduction}

Contemporary second language (L2) pedagogy has attached great importance to learner autonomy (LA) in learning process. Individual learners, however, are not always autonomous in foreign language learning, especially in oral English learning in China. LA in L2, which is an individual factor perceived to facilitate L2 acquisition, has been extensively studied in recent years (e.g. Dickinson, 1995; Little, 1995; Littlewood, 1999; Xu \& Peng, 2004; Hua, 2009). In English as Foreign Language (EFL) context, the study of LA in oral English is of special importance in promoting learners' poor oral English. In fact, LA in oral English should be one of the primary goals of language instruction.

Many studies have been carried out to explore LA in relation to various internal and external factors such as self-efficacy on oral ability, attribution on oral ability, awareness of oral learning, motivation, strategies, teachers and peers, and group dynamics (Boud, 1988; Gao, 2005; Xu, 2007; Wu \& Zhang, 2009). Despite the rich findings from previous research, however, little effort has been devoted to studying LA in conjunction with oral English. In EFL context such as China, cultivation of learner autonomy and oral English ability has always been emphasized. However, the implementation of this guideline is still in question, even for English majors (Liu, 2008). And learner autonomy in oral English remains underaddressed. The present study, inspired by the social constructivism (Williams \& Burden, 1997), aims to incorporate learner autonomy into the oral English learning focusing on Chinese university students.

\section{Literature review}

2.1 Learner autonomy in oral English (LAIOE)

The concept of LA was originally developed by Holec (1981), representing the ability to take charge of one's own learning. Based on the definition of learner autonomy from Holec, many researchers raised revised ones according to 
different contexts and conditions (Dickinson, 1987; Zimmerman, 1989; Little, 1995; Littlewood, 1999; Cotterall, 2000; Xu \& Peng, 2004). Dickinson (1987) defines LA that the learner should take responsibility of all decisions related to learning and the accomplishments of the decisions. Littlewood (1999) indicates that "taking responsibility" involves learners in taking ownership (partial or total) of many processes which had traditionally belonged to the teacher, such as deciding on learning objectives, selecting learning methods and evaluating progress.

There is still scant research into variables affecting LA in oral English among Chinese EFL learners. Xu and Peng (2004) explained LA of English learners in China from five aspects. Based on their opinions, the definition of LAIOE in this study is defined from the following five dimensions: 1) ability to understand teacher's oral teaching aim and requirements; 2) ability to establish oral learning goal and make related plans; 3) ability to make use of oral learning strategies efficiently; 4) ability to monitor the use of oral learning strategies; 5) ability to supervise and evaluate oral learning process and progress.

\subsection{Factors influencing LAIOE}

Findings from research on LA show that LA is an interactively-developed ability, and can be influenced by a variety of factors (Cotterall, 1995). Among these factors, some are learners' internal properties that can be controlled by learners, e.g. learner independence, learner confidence and experiences; others are external factors that cannot be controlled by learners, e.g. the role of the teacher, the role of feedback and classroom environment.

Generally speaking, internal factors include self-efficacy, learner awareness of autonomy, attribution ways, motivation and learning strategies (Xu, 2007, p.61). Since the components of motivation have been included in such factors as LAIOE, learner awareness and attribution in this study, motivation is not regarded as an independent influencing factor in this study. The same applies to strategies because LAIOE also contains English majors' use of oral English learning strategies. Hence, strategy is not regarded as an independent influencing factor, either. Therefore, self-efficacy, learner awareness, attribution ways are the internal factors to be considered in this study.

The external factors include the teacher's role and action, teaching technology, peers and learning environment, social culture and so on $(\mathrm{Xu}, 2007)$. In this study, the influences from teachers and peers on LAIOE will be scrutinized since these two factors are the most frequently-mentioned factors in mainland China.

Based on previous research, five main factors are chosen to be further discussed: self-efficacy, learner awareness, attribution, role of teacher, and peers and atmosphere in class.

\subsection{Self-efficacy}

Self-efficacy (SE) refers to the confidence and belief an individual holds on achieving goals in a specific area (Bandura, as cited in Xu, 2007, p.63). Pintrich (1990) also finds that self-efficacy is positively related to the use of cognitive strategies, metacognitive strategies (planning and monitoring) and effort management which are components of learner autonomy. Many empirical studies prove the influence from self-efficacy to LAIOE (Zimmerman, 1989; Yang, 1999; Lu \& Ding, 2005; Wu \&Zhang, 2009). On the basis of Bandura and Pintrich's viewpoints, self-efficacy influenced oral English learning in four ways: high self-efficacy helps learners choose more difficult communicative activities, facilitates their oral practice, declines their anxiety and depression in oral performance, and improves their persistence in autonomic oral English learning ( $\mathrm{Xu}, 2007, \mathrm{p} .63$ ). To sum up, self-efficacy in oral learning should by any means be brought to the forefront as a key factor influencing LAIOE.

\subsection{Learner awareness on autonomy}

Learner awareness on autonomy refers to the learner's subjective understanding and idiosyncratic beliefs towards autonomy (Qi, 2004). Wenden (1986) indicates that language learners' beliefs about how best to learn a language could provide the logic for their choice of learning strategies, which implies that students' awareness on learning has an effect on their autonomy as the choice of strategies is a part of autonomy. Similar opinion is proposed by Abraham and Vann (1987). And this has been proved by an empirical study (Yang, 1999) indicating that awareness about the value and nature of speaking English could trigger more frequent use of formal oral practice strategies. What should be noticed is that the formation of learner awareness could be influenced by other factors, especially teacher's behaviors. This deserves further exploration.

In this study, learner awareness on oral autonomy (AW) is defined as English majors' beliefs on LAIOE, that is, to what extent they realize their responsibilities in oral learning and accept these responsibilities.

\subsection{Attribution on oral ability}

The explanation an individual gives on his or her own success or failure is called attribution (Xu, 2007, p.65). Attribution on oral ability (AT) is about how the learners explain their achievement in speaking, no matter what 
speaking levels they are at.

Researchers home and abroad believe that the ways of attribution could influence LA behavior. According to Weiner (1976), students' attributions influence their expectancy of future performance, task choice and so on. Palmer and Goetz (1988) also note that attribution can affect students' decisions about when and how to use strategies. Hua (2009) holds the opinion that highly autonomous learners tend to attribute their success to their efforts and ability, while those who are not so successful in both LA and academic achievement tend to attribute their failure to context and luck. If the learner attributes his or her failure to ability, he or she might give up making efforts.

Attribution also has influence on other internal factors, such as learner awareness and self-efficacy, and can further affect learning performance (Schunk, 1983; McCombs, 1988).

\subsection{Role of Teacher}

The teacher is a crucial factor influencing learners' LA (Cotterall, 1995; Little, 1995; Lan \& Zeng, 2004). A study conducted by Cotterall (1995) shows one of the important dimensions is the role of the teacher. Lots of empirical studies suggest that learner autonomy is dependent on teacher autonomy and support (Little, 1995; Lee, 1998). Teachers who are more in favor of cultivating learner autonomy are skilled in helping their students develop autonomy in foreign language learning. Studies in China provide more evidence. Lan and Zeng (2004) suggest that autonomous learning does not deny teacher's participation in the class, but requires teachers to better organize teaching process. This view is supported by Liu (2008) and Hua (2001).

Based on the studies above, we suppose that the teacher plays a key role in development of student's autonomy in oral language learning.

\subsection{Peers and atmosphere in class}

LAIOE may also be influenced by peers in learning environment. Dam (1995) suggests that learner autonomy entails "a capacity and willingness to act independently and in cooperation with others, as a socially responsible person". Zimmerman (1989) mentions that autonomous learning is not determined merely by personal processes because these processes are assumed to be influenced by environmental events. Similarly, Qi (2004) points out that only when students study in the "ideal facilitating environment" can they experience true autonomous learning. The "environment" mentioned above refers to the second language learning context constructed by teachers and classmates. This opinion is consistent with that of Lou (2005). What's more, lots of evidence shows that atmosphere in classroom can be influenced by the teacher (Lu \& Ding, 2005).

\subsection{Social constructivist perspective and the hypothesized model}

Social constructivism (Williams \& Burden, 1997) emphasizes the importance of what the learner brings to any learning situation as an active meaning-maker and problem-solver. Thus the learner (the internal factors) plays a central role in social constructivist theory. This perspective also emphasizes the dynamic nature of the interplay between teachers, learners, context and tasks, and provides a view of learning as arising from interactions with others. Thus this perspective also recognizes the importance of teachers and context within which the learning takes place (the external factors). The task here mainly refers to oral English tasks in this study. Therefore, four key sets of factors are identified to influence the learning process in social constructivist theory-teachers, learners, tasks and contexts. The four factors all interact as part of a dynamic, ongoing process. Social constructivism implies that students autonomously construct their own knowledge through outside information and based on personal experiences; that the teacher should be aware of students' already attained knowledge and create learning environment to efficiently connect old and new knowledge; and that the teacher should encourage students to take part in learning activities, such as cooperative learning and assessments in the groups (Xu, 2007, p.52).

Motivated by the social constructivist perspective and based on previous research, the present study aims to test the relationship of LAIOE and the influential factors. A hypothesized model (see Figure 1) was constructed to present the complicated and interlaced relationships among those factors. This framework of LAIOE consists of five factors: self-efficacy, learner awareness, attribution, role of teacher, and peers and atmosphere in class. The arrows in Figure 1 show how these factors influence each other. 


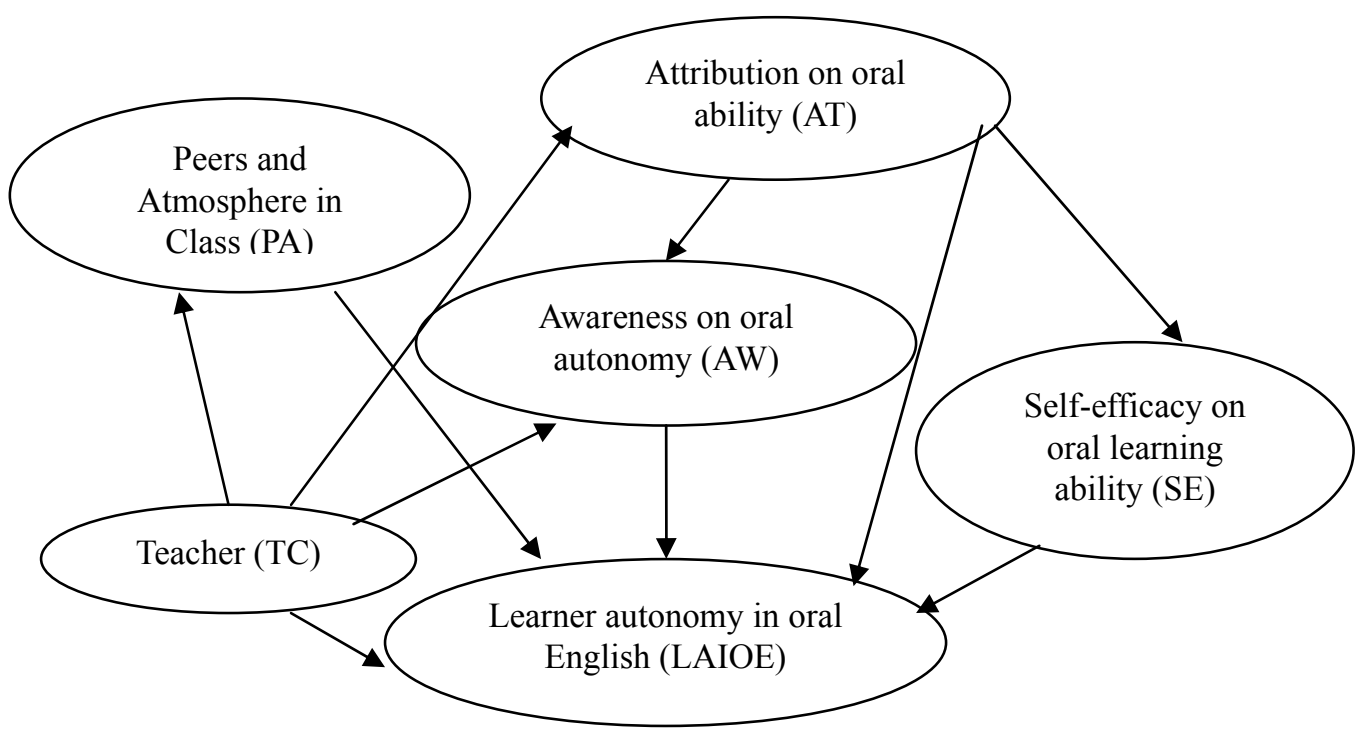

Figure 1. Hypothesized Model Based on Literature Review

\section{The study}

\subsection{Research Questions}

Based on the previous studies, this article tries to answer the following three research questions:

1) What is the current situation of English majors' learner autonomy in oral English (LAIOE)?

2) Do the five main factors -- self-efficacy on oral learning ability (SE), attribution on oral ability (AT), role of teacher (TC), peers and atmosphere in class (PA) and awareness on oral autonomy (AW) -- correlate with LAIOE?

3) What are the relationships among those factors and LAIOE and can they construct a path model? Is the hypothesized model verified by the data?

In order to attain enough data for analyzing the current situation of LAIOE and verify the hypothesized model above, the method of questionnaires on a large scale was utilized. The study adopted two phases of data collecting. Phase I, the pilot study, involved piloting the initial questionnaires on a small scale, using exploratory factor analyses (EFAs) to see factor loadings and Cronbach's $\alpha$, aiming at data reduction and, more importantly, identification of the embedded factor structures (Peng, 2010). Phase II was the main study involving data analyzing and model verification.

\subsection{Phase I -- Pilot study}

In the pilot study, six scales (testing learner autonomy in oral English, self-efficacy, attribution, the role of the teacher, peers and atmosphere in class and awareness of autonomy respectively) are used to collect the data to test the items' reliability and validity.

\section{Learner Autonomy in Oral English (LAIOE)}

The pilot questionnaire of LAIOE was adapted from Xu's (2007) scale measuring LA in listening, which tested learner autonomy in oral English from 5 aspects (or by five subcomponents). 24 items were chosen and measured in the pilot study. Cronbach's $\alpha$ of this questionnaire was $.892(\mathrm{~N}=127)$.

\section{Self-efficacy on oral learning ability (SE)}

This scale was translated and adapted from German Psychologists Schwarzer and Jerusalem's (1995) General Perceived Self-Efficacy Scale. 10 items were adapted to meet the need of this study. For example, the original item "if I try my best, I can always solve the problems" was changed to "if I try my best and make efforts, I can solve most problems in the improvement of oral English". Cronbach's $\alpha$ of this questionnaire was $.872(\mathrm{~N}=127)$.

\section{Awareness on oral autonomy $(A W)$}

This questionnaire was adapted from the questionnaire of Learner Autonomy Awareness in China translated by Qi (2004). Cronbach's $\alpha$ of this questionnaire was .668 ( $\mathrm{N}=127)$. 


\section{Attribution on oral ability (AT)}

This scale shows how much and to what extent the students attribute their oral achievements or failures to their own efforts and capabilities, which can be called as introverted attribution. 16 items were translated and adapted from Multidimensional-Multiattributional Causality Scale (MMCS) designed by Leftcourt et al. (1979). For example, the item in the original questionnaire "In my case, the good grades I receive are always the direct result of my efforts" was modified into "In my case, the good grades I received in the field of oral English are always the direct result of my efforts". Cronbach's $\alpha$ of this questionnaire was .611 ( $\mathrm{N}=127)$.

\section{The role of the Teacher (TC)}

We mainly adopted the questionnaire of College Teacher's Role in Cultivating Students' Learner Autonomy designed by $\mathrm{Xu}$ (2007), and one item (Item13) was added based on the perspective of Wang (2011) that teacher should negotiate with students about study contents, homework and examination system to promote their autonomy. Cronbach's $\alpha$ of this questionnaire was $.904(\mathrm{~N}=127)$.

\section{Peers and Atmosphere in Class (PA)}

The initial questionnaire of PA contained 10 items adapted from Chang's (2007) questionnaire on autonomy and group dynamics. Cronbach's $\alpha$ of this questionnaire was .729 ( $\mathrm{N}=127)$.

As a result, the initial questionnaires included 82 items overall. All the items were measured on a 5-point Likert scale. Generally, 1-point represents strongly disagree and 5-point means strongly agree. The Cronbach's $\alpha$ of the initial questionnaires in the Pilot Study is .886. These questionnaires were piloted among 127 English majors who came from a second-tier college in Jiangxi Province.

\subsection{Phase II -- the study}

Phase II is the main study involving the process of sending modified questionnaires on a large scale. After analyzing Cronbach's $\alpha$ of the initial questionnaire and testing the construct validity of each sub-scale by factor analyses, some deletions and modifications were made to improve the quality of the questionnaire -- 13 items with low factor loadings $(<0.3)$ were deleted to enhance the reliability and the validity. Thus only 69 items were left in the formal questionnaire. The Cronbach's $\alpha$ of the formal questionnaire has risen to .923. (see Table 1).

Table 1. Reliability of the Instruments in Phases II

\begin{tabular}{|c|c|c|c|}
\hline Questionnaire & $\begin{array}{l}\text { Number of } \\
\text { participants }\end{array}$ & $\begin{array}{l}\text { Number of } \\
\text { Items }\end{array}$ & Cronbach's $\alpha$ \\
\hline LAIOE & 478 & 23 & .906 \\
\hline SE & 478 & 10 & .824 \\
\hline AW & 478 & 8 & .664 \\
\hline $\mathrm{AT}$ & 478 & 10 & .656 \\
\hline $\mathrm{TC}$ & 478 & 12 & .875 \\
\hline PA & 478 & 6 & .773 \\
\hline TOTAL & 478 & 69 & .923 \\
\hline
\end{tabular}

Note. LAIOE = learner autonomy in oral English; $\mathrm{SE}=$ self-efficacy on oral learning ability; $\mathrm{AW}=$ awareness on oral autonomy, $\mathrm{AT}=$ attribution on oral ability, $\mathrm{TC}=$ teacher, $\mathrm{PA}=$ peers and atmosphere in class.

In order to ensure the authenticity and validity of the data, a new group of subjects recruited from the same sample pool was utilized (Peng, 2010) and the total number of sample increased a lot -- 520 English majors from 7 different universities or colleges in Jiangxi were invited to take part in the survey. Among all the subjects, 478 offered fully valid questionnaires. Of these students, 160 were recruited into the first-tier (i.e., national key universities); 145 were enrolled into second-tier universities and 173 in the third-tier colleges. They were sophomores or juniors who had taken oral English class for at least one year and had established their own regular learning styles.

All the items were measured on a 5-point Likert scale. The statements of some items were intentionally inverted so that the meanings of the numbers were also inverted to help ensure authenticity and validity. When assessing the results, these special items were recalculated $(1=5,2=4,3=3,4=2,5=1)$. 


\subsection{Data collection and analysis}

All the questionnaires were administered at classroom time and collected with the help of their teachers in two weeks.

All the data were analyzed by SPSS17.0 in the following steps. First, descriptive statistics (including mean, standard deviation) were obtained to detect the overall situation of LAIOE employed among the English majors. Next, correlation analysis was employed to see if there were any relations between the factors and LAIOE. Finally, stepwise regression analyses were carried out to show the regression paths among those factors, and a regression model was made to test the hypothesized model.

\section{Results and discussion}

\subsection{Overall situation of LAIOE}

The mean score of items in the LAIOE scale implies the English majors' overall situation of oral autonomy. The higher the mean score is, the more autonomous the students are in oral learning. A total mean score from 1 to 3 is regarded as low autonomy in oral English learning, and 3 to 4 indicates a moderate level. If mean score surpasses 4 and even approaches to 5, it means that the student is highly autonomous in oral English learning (Liu \& Jackson, 2008).

The mean score of students' LAIOE ranges from 1.48 to 4.35 (see Table 2). The table also shows a mean of 2.7798, a median of 2.6957, and a mode of 2.61; all three indexes are lower than 3, manifesting that English majors are obviously not autonomous enough in oral English learning. This may indicate that learners interpret oral English tasks as difficult and not so meaningful for individuals. Since oral English may threaten their face, and will not be tested in important exams, they may spend less time and energy in oral English tasks.

Table 2. Descriptive results of LAIOE

\begin{tabular}{lllllll}
\hline & Mean & Median & Mode & Std.Deviation & Minimum & Maximum \\
\hline LAIOE & 2.7798 & 2.6957 & 2.61 & 0.485 & 1.48 & 4.35 \\
\hline
\end{tabular}

69 per cent of the students got low mean scores of LAIOE, ranging from 1 to 3 . Therefore, almost 7 out of 10 students are not autonomous enough in oral English learning.

\subsection{Correlation analysis between the five factors and LAIOE}

Table 3 shows the results of descriptive statistics of the subscales of the questionnaire. It shows that students' AW and AT have reached a moderate level (3.38 and 3.40 respectively), indicating that English majors can be aware of their responsibilities in oral English learning, and they usually attribute oral English achievement to their own efforts. The mean score of SE is 2.96, which is a little lower than the moderate level (3.0), showing that students don't have enough confidence in their oral English learning ability. TC and PA both exceed 3, which indicate that the teacher and peers create a favorable environment for oral English learning.

Table 3. Results of descriptive analyses of the questionnaire

\begin{tabular}{llll}
\hline Subscales & $\mathrm{N}$ & Mean & Std. Deviation \\
\hline LAIOE & 478 & 2.78 & .485 \\
SE & 478 & 2.96 & .572 \\
AW & 478 & 3.38 & .521 \\
AT & 478 & 3.40 & .515 \\
TC & 478 & 3.04 & .625 \\
PA & 478 & 3.07 & .743 \\
\hline
\end{tabular}

Note: LAIOE= Learner autonomy in oral English; $\mathrm{SE}=$ self-efficacy on oral learning ability; $\mathrm{AW}=$ awareness on oral autonomy, $\mathrm{AT}=$ attribution on oral ability, $\mathrm{TC}=$ teacher, $\mathrm{PA}=$ peers and atmosphere in class.

Then correlation analysis was conducted to examine the relationship between the students' LAIOE and five influencing factors (see Table 4). 
Table 4. Correlations between LAIOE and five influencing factors

\begin{tabular}{lllllll}
\hline Factors & LAIOE & SE & AW & AT & TC & PA \\
\hline SE & $.585^{* *}$ & 1 & & & & \\
AW & $.402^{* *}$ & $.390^{* *}$ & 1 & & & \\
AT & $.311^{* *}$ & $.312^{* *}$ & $.402^{* *}$ & 1 & & \\
TC & $.384^{* *}$ & $.306^{* *}$ & $.212^{* *}$ & $.176^{* *}$ & 1 & \\
PA & $.335^{* *}$ & $.385^{* *}$ & $.246^{* *}$ & .084 & $.514^{* *}$ & 1 \\
\hline
\end{tabular}

Note: ${ }^{* *} \mathrm{p}<.01$. LAIOE $=$ learner autonomy in oral English; $\mathrm{SE}=$ self-efficacy on oral learning ability; $\mathrm{AW}=$ awareness on oral autonomy, $\mathrm{AT}=$ attribution on oral ability, $\mathrm{TC}=$ teacher, $\mathrm{PA}=$ peers and atmosphere in class.

Table 4 shows that LAIOE are significantly and positively correlated with all the five factors - SE, AW, AT, TC, $\mathrm{PA}(\mathrm{r}=.585, .402, .311, .384, .335$, respectively, $\mathrm{p}<.01)$. Students who scored higher on the SE, AW, AT, TC, and PA tended to score higher on the LAIOE. On the other hand, students who had lower self-efficacy and awareness, who seldom attributed their success in speaking to their efforts and capabilities, and whose teacher and learning peers were not autonomous and influential enough, scored much lower in LAIOE.

Correlations are also found among those five influencing factors. SE is positively correlated with AW, AT, TC, PA $(\mathrm{r}=.390, .312, .306, .385$, respectively, $\mathrm{p}<.01)$. Higher self-efficacy means higher awareness, more self attribution, better effects from teachers and classmates. AW is relatively highly correlated with AT $(r=.402, p<.01)$, indicating that AT might influence AW, which accords with Hsieh and Schallert's opinion (2008) that attributions could influence learners' beliefs as well as awareness. Besides SE, TC is also correlated with AT and AW ( $\mathrm{r}=.176, .212$, respectively, $\mathrm{p}<.01)$, though the coefficients are not so high. They prove the mighty influence on English majors from teachers. TC and PA are correlated closely as the coefficient is $.514(\mathrm{p}<.01)$, which accords with a lot of previous studies (Lu \& Ding, 2005; Fu, 2007) and proves the close relationship between the teacher's behavior and students' actions.

The analyses so far clearly support the opinions in the literature above that these five factors are closely related to LAIOE and there indeed exist complicated correlations among the factors. Thus, further analyses on regression of the factors to explore clearer relations can be carried out.

\subsection{The regression model and discussion}

In order to see the relations between the factors and LAIOE, we conducted regression analyses with all the five factors as the predictors (independent variables) and LAIOE as the dependent variable.

However, not all of the five measured factors entered the regression model - four were included in the model that related to LAIOE as significant predictors: teacher (TC), awareness on oral autonomy (AW), self-efficacy on oral learning ability (SE), and attribution on oral ability (AT) (Table 5); while peers and atmosphere didn't enter the model.

Table 5 shows summary of the parameters of the regression model. The R Square is .421 , which means that the four variables could explain $42.1 \%$ of the variance of LAIOE.

Table 5. Summary of predictors of LAIOE

\begin{tabular}{llll}
\hline Number of included predictors & $\mathrm{R}$ & $\mathrm{R}^{2}$ & Adjusted $\mathrm{R}^{2}$ \\
\hline 4 & .649 & .421 & .416
\end{tabular}

Predictors (Constant): $\mathrm{SE}=$ self-efficacy on oral learning ability; $\mathrm{AW}=$ awareness on oral autonomy, $\mathrm{AT}=$ attribution on oral ability, $\mathrm{TC}=$ teacher. Dependent Variable: $\mathrm{LAIOE}=$ Learner autonomy in oral English.

As shown in Table 6, among the four variables above, SE is the most powerful predictor of learner autonomy in oral English $(\beta=.438, \mathrm{t}=11.019, \mathrm{p}=.000)$; followed by $\mathrm{TC}(\beta=.203, \mathrm{t}=5.480, \mathrm{p}=.000), \mathrm{AW}(\beta=.158, \mathrm{t}=3.914, \mathrm{p}$ $=.000)$, and AT $(\beta=.076, \mathrm{t}=2.943, \mathrm{p}=.043)$. 
Table 6. Regression coefficients and significance of factors influencing LAIOE

\begin{tabular}{llll}
\hline & \multicolumn{2}{l}{ Learner autonomy in oral English (LAIOE) } \\
\cline { 2 - 4 } predictors & $\beta$ & $\mathrm{t}$ & Sig. \\
\hline SE & .438 & 11.019 & .000 \\
TC & .203 & 5.480 & .000 \\
AW & .158 & 3.914 & .000 \\
AT & .076 & 2.943 & .043
\end{tabular}

Dependent variable: LAIOE= learner autonomy in oral English. Predictors: $\mathrm{SE}=$ self-efficacy on oral learning ability; $\mathrm{AW}=$ awareness on oral autonomy, $\mathrm{AT}=$ attribution on oral ability, $\mathrm{TC}=$ teacher.

SE's influence on LAIOE is so significant that this finding can well prove Xu's viewpoints (2007, p.63). Xu points out that SE can affect students in the following ways: choice of task, establishment of learning aim, efforts made for fulfilling the task, emotions experienced when they take up oral learning, autonomous strategies used during the whole process, and even the self-evaluation of oral learning. These are corresponding to the contents in LAIOE scale.

$\mathrm{TC}$, in spite of its classification of external factor, exceeds the impacts from other internal factors, such as AW and AT. It seems that, the more guidance, supervision and inspiration the teacher gives to the students, the more the students will attain and modulate their own learning processes. Ferrer-Caja and Weiss (2000), Voller (1997) and other researchers state the similar opinions on teachers' influence on LA in language learning.

AW can directly influence behavior, which has also been proved by the regression coefficients. In other words, students who tend to show more interests in oral activities, who have more intensive motivation to fulfill oral tasks, and who believe that students themselves should be more responsible for oral learning, perform better in LAIOE. This empirical finding is similar to Little's (1995) opinion that when learners are aware of their responsibilities in learning, they will study more autonomously.

AT also directly predicts LAIOE, though the coefficient is not very high $(\beta=.076, p=.043)$. However, the importance of AT mentioned in literature review may imply indirect relations between AT and LAIOE, In other words, AT may influence LAIOE through the impacts of other factors. This possibility will be discussed later.

\subsection{The regression coefficients among the five influencing factors}

After further regression analyses, 6 paths among the factors were discovered. They were the path from TC to PA, the path from TC to AT, the path from PA to SE, the path from AT to SE, the path from AT to AW, and the path from SE to AW. These discovered paths are shown in Table 7.

Table 7. The regression coefficients among the five influencing factors

\begin{tabular}{llll}
\hline Predictor--DV & $\beta$ & $\mathrm{t}$ & Sig. \\
\hline TC -- PA & .514 & 13.084 & .000 \\
TC --AT & .176 & 3.891 & .000 \\
\hline PA --SE & .362 & 8.933 & .000 \\
AT --SE & .282 & 6.955 & .000 \\
\hline AT--AW & .311 & 7.374 & .000 \\
SE--AW & .293 & 6.950 & .000 \\
\hline
\end{tabular}

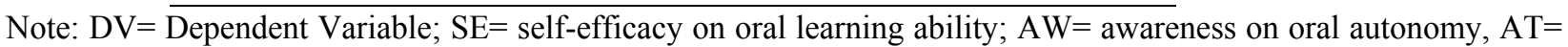
attribution on oral ability, $\mathrm{TC}=$ teacher, $\mathrm{PA}=$ peers and atmosphere in class.

TC is closely related to PA $(\beta=.514, \mathrm{t}=13.084, \mathrm{p}=.000)$. The results are consistent with previous research (Lan \& Zeng, 2004; Xu, 2007, p.78). The regressive coefficients of TC to AT $(\beta=.176, t=3.891, p=.000)$ is also significant. This result is consistent with previous research $(\mathrm{Li}, 2004)$ which emphasized that the teacher could guide students to make right attribution on their achievements and failures in oral learning.

To sum up, the role of teacher is important to student's development of oral autonomy, since it not only directly influences LAIOE, but also indirectly influences LAIOE through AT. 
PA and AT have relatively moderate influence on $\mathrm{SE}(\beta=.362, \mathrm{t}=8.933 ; \beta=.282, \mathrm{t}=6.955$ respectively, $\mathrm{p}=.000)$. The regression from PA to SE is consistent with Social constructivist view -- individuals tend to internalize external learning skills (excellent peers' behavior) into their own mechanism and then imitate their behavior and regulate their own behavior. In addition, Xu (2007, p.65) mentions that students' attribution on their achievements and failures in learning could change self-efficacy. These two paths were verified by the data.

AT has higher regressive coefficients $(\beta=.311, \mathrm{t}=7.374, \mathrm{p}=.000)$ to $\mathrm{AW}$, and that of SE is a little lower $(\beta=.293, \mathrm{t}=$ $6.950, \mathrm{p}=.000)$. These two paths were consistent with previous studies (Xu, 2007).

\subsection{The path model of LAIOE and five influencing factors}

After synthesizing the results of regression model mentioned above, a path model can be established to manifest relations among those factors and LAIOE. (see Figure 2)

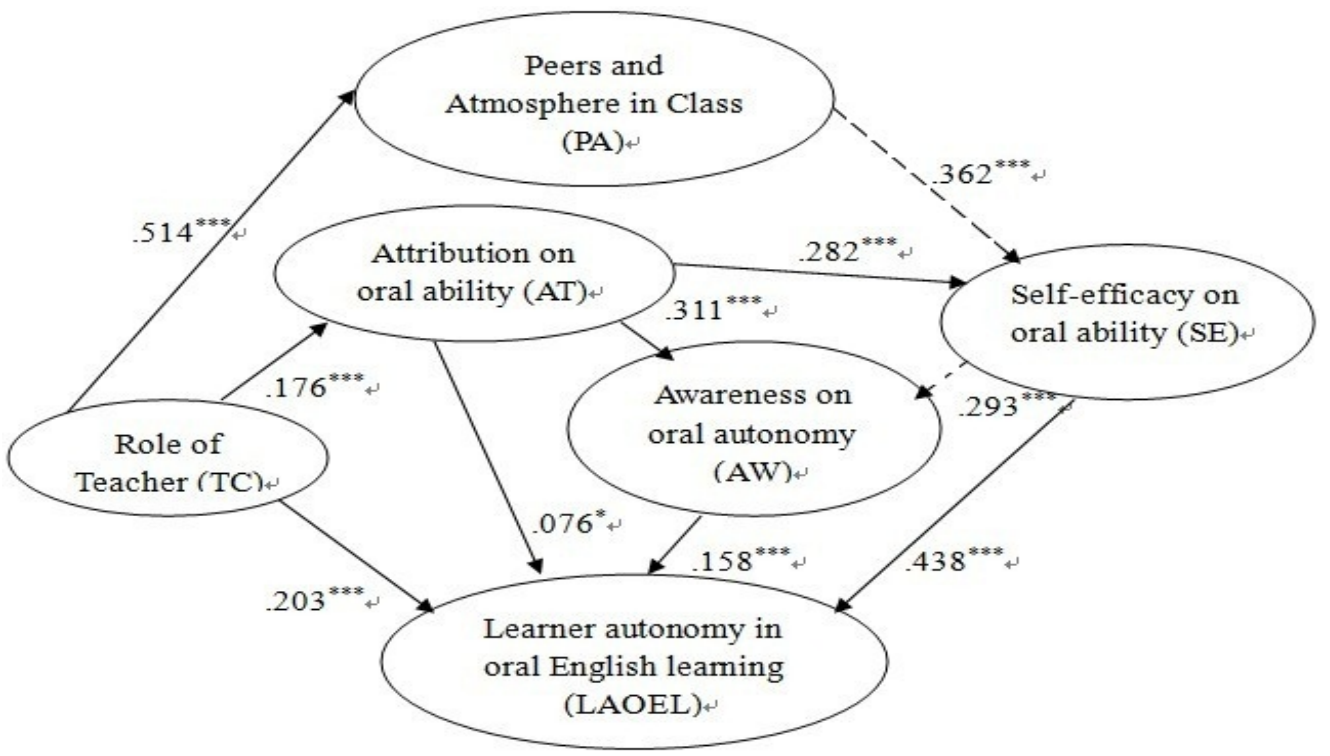

Figure 2. The path model of LAIOE and five influencing factors

Student's self-efficacy on oral learning ability is the most influential and significant factor in the development of LAOLE, just as the data show $(\beta=.438, \mathrm{t}=11.019, \mathrm{p}=.000)$. This is consistent with the social constructivist view of language learning that learner internal factor plays central role in learning process. Learners learn what is meaningful to them and learn in the ways that are meaningful to them. Learning is closely linked to how people feel about themselves. If a person has a low self-efficacy, then it is likely that he or she will feel a sense of embarrassment at using the language and will avoid risk-taking situations or initiating conversations in the second language. If individuals have high self-efficacy, they are likely to set themselves more optimistic goals, to engage in situations which involve risks and to seek out opportunities to use the language.

The teacher factor also plays crucial roles at the same time. Teacher (TC) directly influences PA and AT according to the data analyses above $(\beta=.514, \mathrm{t}=13.084, \mathrm{p}=.000 ; \beta=.176, \mathrm{t}=3.891, \mathrm{p}=.000)$. A powerful prediction of PA from $\mathrm{TC}$ is detected here as the value of $\beta$ is as high as .514. TC's great influence on AT has been discussed frequently in previous literature $(\mathrm{Xu}, 2007)$, and this relation is also testified by the regression analyses.

The teacher factor is also an independent factor in social constructivist theory, and thus the importance of teachers is also confirmed since it is a powerful predictor of LAIOE. Teachers possess particular views, beliefs and attitudes, which will determine their own actions and which in turn will have an influence on the actions of their learners. The importance of the teacher can be explained by the fact that Chinese students mainly learn English in classroom, and have few opportunities to acquire the language outside classroom. Teachers exert most important influence on classroom learning, peers and atmosphere, and other context factors.

Two new paths (marked by dotted lines in Figure 2) were found in the data analyses: PA has a direct influence on SE $(\beta=.362, \mathrm{t}=8.933, \mathrm{p}=.000)$ and SE also has a direct influence on $\mathrm{AW}(\beta=.293, \mathrm{t}=6.950, \mathrm{p}=.000)$. These findings are in accord with Janice's (as cited in Xu, 2007, p.82) research.

Two paths anticipated in hypothesized model are not detected by the data analyses: one is from PA to LAIOE, and 
the other is from TC to AW. Although PA does not show a direct regression to LAIOE, it is retained because it is logically probable that this variable might affect LAIOE in a more indirect way. From Figure 2 we can see PA has influence on SE $(\beta=.362, \mathrm{t}=8.933, \mathrm{p}=.000)$, and SE has a strong influence on LAOIE. This confirms the social constructivist theory that the influence of external factors should be realized through internal factors of learners, and this kind of internalization might not be achieved by every student.

From the data in this study, the teacher factor (TC) could not directly predict student's autonomous awareness in oral learning (AW). The reason may lie in the students. Sometimes, the teacher does directly tell students how to learn oral English autonomously and provide them with an amount of speaking strategies and resources, but the students are not ready to accept the teacher's advice; even if they accept these autonomous concepts and want to make a change sincerely, they still have difficulty in transforming ideas into actions due to laziness and a lack of appropriate supervision.

TC, not influenced by any other factor in this study, can indirectly influence LAIOE via the following five paths: TC - PA - SE - LAIOE, TC - AT - LAIOE, TC - AT - AW - LAIOE, TC - AT - SE - LAIOE, TC - AT - SE - AW LAIOE. In those five paths, all factors are included, illustrating the complex and prevailing impacts of TC. This again proves that the teacher plays one of the most important roles in LAIOE.

The final model appeared to provide an adequate fit to the data. It accounted for $42.1 \%$ of the variance of LAIOE (see Table 5), indicating that the joint effect of the four variables (SE, TC, AW, AT) adequately predicted the variation of LAIOE. And the fifth variable-PA - affects LAIOE through SE in an indirect way.

\section{Conclusions}

\subsection{Major findings}

In this study, through all the analyses above, we can draw the following conclusions about LAIOE of English majors in China.

(1) The mean score of students' LAIOE is 2.7798 , and 69 per cent of the students got low mean scores of LAIOE, ranging from 1 to 3. This indicates English majors are not autonomous enough in oral learning, and reflects the unsatisfied oral learning status of English majors in China. They cannot establish oral learning goals or set plans for themselves. It is also rather difficult for them to make use of oral learning strategies. In spite of these, English majors are able to make right attributions, and they are clearly aware of their responsibilities in oral learning. The reasons why English majors are not autonomous enough can be divided into two parts - objective and subjective elements. From objective aspect, the long-existed teacher-centered teaching model results in students' dependence on teachers, and teachers always focus on the instruction of knowledge and skills, overlooking the cultivation of learning strategies. From subjective aspect, students regard autonomous oral activities as difficult tasks or they simply do not recognize the importance of oral English learning.

(2) The results show that five factors (SE, AW, AT, TC, PA) are all significantly and positively correlated with LAIOE. So the factors investigated in this study are truly influential factors. Among them, SE has the highest correlation with LAIOE $(\mathrm{r}=.585, \mathrm{p}<.01)$ and AT has the lowest $(\mathrm{r}=.311, \mathrm{p}<.01)$. Therefore, self-efficacy is the most important internal factor that affects LAIOE and it plays an important role in this model. To both the teacher and English majors, the enhancement of SE should be emphasized.

(3) The regression analyses reveal that SE, TC, AW, AT are all good predictors of LAIOE, and the four variables could explain $42.1 \%$ of the variance of LAIOE. But PA does not predict LAOLE directly. Six paths among the factors were discovered, which reflects complex relationship among them.

Illuminated by the social constructivist perspective, the path model of LAIOE integrating the five influencing factors is verified by the data (see Figure 2). The model shows the vital role of SE, which is the most powerful predictor of LAIOE. From social constructivist perspective, learners should make sense of the learning situations, and learner autonomy should be self-activated and internalized. Among other factors, TC is the second predictor in this model, and TC has extensive influences on other factors (it can directly influence PA, AT, and LAIOE simultaneously). The five influencing factors all interact as part of a dynamic, ongoing process in LAIOE.

\subsection{Limitations and suggestions}

This study is heuristic in being the first effort to investigate the influential factors on LAIOE in China's EFL context. Owing to various constraints, however, there were some limitations in this study.

First, because LAIOE has a broad influential range, it is impossible to cover every aspect of them (such as motivation, learning environment, social-culture, teaching technology and so on). This study only considered five main factors (SE, TC, AW, AT, PA) that were perceived to be particularly relevant to the current research. 
Investigating a wider strand of influential factors may be a worthwhile direction in future study.

Second, the regression path model could tell the relationships and show some hints, but further analyses and verification of causal relationships need advanced solutions by more complex methods, such as Structural Equation Model.

\section{References}

Abraham, R.G., \& Vann, R.J. (1987). Strategies of two language learners: a case study. In: Wenden, A.L, Rubin, J. (Eds.), Learner strategies in language learning. Prentice-Hall, Englewood Cliffs, NJ, 85-102.

Boud, D. (1988). Moving towards autonomy. In D. Boud (Ed.), Developing student autonomy learning( $2^{\text {nd }}$ ed.). London: Kogan Page,17-39.

Chang, L.Y. (2007). The influence of group processes on learners' autonomous beliefs and behaviors. System, 35, 322-337. http://dx.doi.org/10.1016/j.system.2007.03.001

Cotterall, S. (1995). Readiness for autonomy: investigating learner beliefs. System, 2, 195-205 http://dx.doi.org/10.1016/0346-251X(95)00008-8

Cotterall, S. (2000). Promoting learner autonomy through the curriculum: principles for designing language courses. ELT journal volume, 2, 109-110. http://dx.doi.org/10.1093/elt/54.2.109

Dam, L. (1995). Learner autonomy: from theory to classroom practice. Dublin: Authentik.

Dickson, L. (1987). Autonomy, self-directed learning and individualization. ELT documents 103. London: The British Council.

Dickinson, L. (1995). Autonomy and motivation a literature review. System, 2, 165-174. http://dx.doi.org/10.1016/0346-251X(95)00005-5

Ferrer-Caja, Emilio, \& Maureen R. Weiss. (2000). Predictors of intrinsic motivation among adolescent students in physicaleducation. Research quarterly for exercise and sport, 71(3), 267-79. http://dx.doi.org/10.1080/02701367.2000.10608907

$\mathrm{Fu}$, Jingyuan. (2007). Developing learner autonomy for oral language on the base of emergent metacognition, US-China Education Review, 9, 38-45.

Gao, Ji-li. (2005). A survey of the articles concerning research on FL autonomous learning, Foreign language education, 1, 60-63.

Holec. (1981). Autonomy and foreign language learning. Oxford: Pergamon Press.

Hsieh, P., \& Schallert, D.L. ( 2008). Implications from self-efficacy and attribution theories for an understanding of undergraduates' motivation in a foreign language course. System, 33, 513-532. http://dx.doi.org/10.1016/j.cedpsych.2008.01.003

Hua, Weifen. (2001). The place of foreign language teachers in students' initiative learning model. Foreign languages research, 3, 76-79.

Hua, Weifen. (2009). On motivations and autonomy of EFL learners. Foreign languages research, 1, 57-62.

Lan, Changqin \& Zeng Jie. (2004). Reflections on cultivating language learners' autonomy in China. Foreign language world, 4, 24-30.

Lee, Icy. (1998). Supporting greater autonomy in language learning. ELT journal, 4, 282-290. http://dx.doi.org/10.1093/elt/52.4.282

Leftcourt, H. M., Von Baeyer, C. L., Ware, E. E., \& Cox, D. J. (1979). The multidimensional-multiattributional causality scale: The development of a goal specific locus of control scale. Canadian journal of behavioral science, 11, 286-304. http://dx.doi.org/10.1037/h0081598

Li Changzhen. (2004). A study on non-English majors' learning behaviors based on attribution theory. Foreign language world, $6,41-51$.

Liu, Meihua \& Jackson J. (2008). An exploration of Chinese EFL learners' unwillingness to communicate and foreign language anxiety. The modern language journal, 71-86. http://dx.doi.org/10.1111/j.1540-4781.2008.00687.x

Liu, Qin. (2008). A study on Chinese undergraduates' oral proficiency. Modern foreign language, 1, 83-89.

Little, D. (1995). Learning as dialogue: the dependence of learner autonomy on teacher autonomy. Science, 2, 175-181. http://dx.doi.org/10.1016/0346-251X(95)00006-6 
Littlewood, W. (1999). Defining and developing autonomy in East Asian contexts. Applied linguistics, 1, 71- 94. http://dx.doi.org/10.1093/applin/20.1.71.

Lou, He-ying. (2005). Self-assessment and peer-assessment: effective ways of developing learner autonomy. Foreign language education, 4: 60-63.

$\mathrm{Lu}$, Ming, Ding Wan-jiang. (2005). An alternate explanation of affective factors in oral English teaching. Foreign language world, 2, 52-57.

McCombs, B.L. (1988). Motivational skills training: combining metacognitive, cognitive, and affective learning strategies. In Weinstein, C.E., Goetz, E.T., Alexander, P.A.(Eds), Learning and study strategies: issues in assessment, instruction, and evaluation. Academic Press, San Diego, CA, 141-169. http://dx.doi.org/10.1016/B978-0-12-742460-6.50015-3

Palmer, D.J., Goetz, E.T. (1988). Selection and use of study strategies: the role of the students' beliefs about self and strategies, In: Weinstein, C.E., Goetz, E.T., \& Alexander, P.A. (Eds), Learning and study strategies: issues in assessment, instruction, and evaluation. Academic Press, San Diego, CA, 41-61. http://dx.doi.org/10.1016/B978-0-12-742460-6.50010-4

Peng, Jian-E \& Woodrow, L. (2010). Willingness to communicate in English: a model in the Chinese EFL classroom context. Language learning, 4, 834-876. http://dx.doi.org/10.1111/j.1467-9922.2010.00576.x

Pintrich, P.R., \& De Groot, E.V. (1990). Motivational and self-regulated learning components of classroom academic performance. Journal of educational psychology, 82,33-40. http://dx.doi.org/10.1037/0022-0663.82.1.33

Qi, Hong-bo. (2004). A survey on autonomy consciousness of second language learners in China. Foreign language education, 3, 90-93.

Schunk, D.L. (1983). Ability versus effort attributional feedback: differential effects on self-efficacy and achievement. Journal of educational psychology, 75, 848-856. http://dx.doi.org/10.1037/0022-0663.75.6.848

Schwarzer, R. \& Jerusalem, M. (1995). Optimistic self-beliefs as a resource factor in coping with stress. In S. E. Hobfoll \& M. W. deVries (Eds.), Extreme stress and communities: impact and intervention. Dordrecht, The Netherlands: Kluwer 159-177. http://dx.doi.org/10.1007/978-94-015-8486-9_7

Voller, P. (1997). Does the teacher have a role in autonomous learning? In: P. Benson \& P. Voller (Eds.).Autonomy and independence in language learning. London: Longman, 98-113.

Wang, P. (2011). Constructivism and learner autonomy in foreign language teaching and learning: to what extent does theory inform practice? Theory and practice in language studies, 3, 273-277. http://dx.doi.org/10.4304/tpls.1.3.273-277

Weiner, B. (1976). Attribution theory, achievement motivation, and the educational process. Review of educational research, 42, 201-215.

Wenden, A.L. (1986). Helping language learners think about learning. English language teaching journal, 40, 3-12. http://dx.doi.org/10.1093/elt/40.1.3

Williams, M. \& Burden, R. L. (1997). Psychology for language teachers. The Press of the University of Cambridge.

Wu, Xiyan \& Zhang Qingzong. (2009). Correlation between self-efficacy, learning strategies, self-regulated learning and academic achievements. Foreign language education, 3, 43-47.

$\mathrm{Xu}$, Jinfen. (2007). Autonomy in college foreign language learning - from theory to practice. China Social Sciences Press.

$\mathrm{Xu}$, Jinfen \& Peng Renzhong (2004) A survey and analysis of non-English majors undergraduates' autonomous English learning competence. Foreign language teaching and research, 1, 64-68.

Yang, Nae-Dong (1999) The relationship between EFL learners' beliefs and learning strategy use. System, 27, 515-535. http://dx.doi.org/10.1016/S0346-251X(99)00048-2

Zimmerman, B.J. (1989) A social cognitive view of self-regulated academic learning. Journal of educational psychology, 3, 329-339. http://dx.doi.org/10.1037/ 0022-0663.81.3.329

Supporting Information

Additional Supporting Information will be offered upon request to the authors.

Appendix A: The formal questionnaire 